\title{
ERRATUM
}

\section{Bronze Age metal circulation in China - ERRATUM}

\author{
A.M. Pollard, P. Bray, P. Hommel, Y.-K. Hsu, R. Liu \& J. Rawson
}

https://doi.org/10.15184/aqy.2017.45

In the article by Pollard et al. (2017), Figure 2 was incorrectly duplicated as Figure 5. The correct Figure 5 is given below.

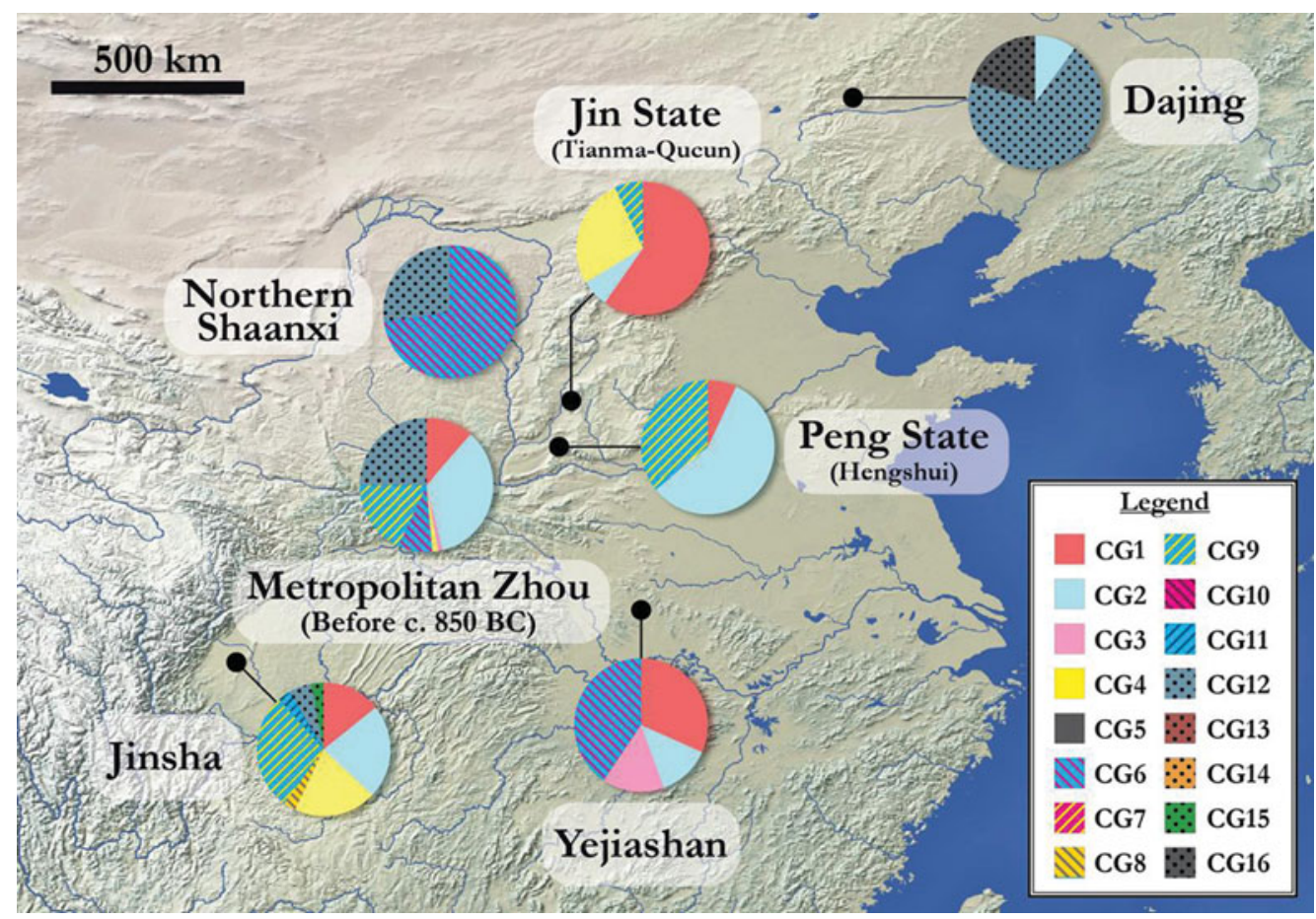

Figure 5. Spatial variation of Copper Groups in Western Zhou.

\section{Full citation}

Pollard, A.M., P. Bray, P. Hommel, Y.-K. Hsu, R. Liu \& J. Rawson 2017. Bronze Age metal circulation in China. Antiquity 91: 674-87. https://doi.org/10.15184/aqy.2017.45 